\title{
Penyuluhan Sampah dan Teknik Pengolahannya di Kelurahan 14 Ulu Palembang
}

\author{
Meli Astriani $^{*}$, Erni Angraini ${ }^{1}$, Kholillah ${ }^{1}$ \\ ${ }^{1}$ Program Studi Pendidikan Biologi, Fakultas Keguruan dan Ilmu Pendidikan, Universitas Muhammadiyah \\ Palembang, Jln. Jenderal Ahmad Yani 13 Ulu Seberang Ulu II, Palembang, Sumatera Selatan, 30263 \\ *Email Korespondensi: meliastriani.g201@gmail.com
}

\begin{abstract}
Abstrak
Sampah merupakan permasalahan besar bagi kita semua seiring dengan semakin meningkatnya jumlah penduduk dan tingkat pertumbuhan industri. Sistem pengelolaan sampah dibutuhkan peran dari pemerintah dan masyarakat dalam mewujudkan lingkungan yang bersih, rapi, dan sehat. Salah satu upaya yang dilakukan yaitu dengan mengadakan penyuluhan mengenai sampah dan berbagai teknik pengolahannya, sehingga diharapkan dapat meningkatkan pengetahuan hidup bersih dan sehat untuk menekan angka penduduk yang terserang penyakit, dan menciptakan masyarakat yang aktif berpartisipasi dan sadar akan kebersihan lingkungan. Metode yang digunakan dalam penyuluhan masyarakat adalah metode partisipatif atau Pendidikan Orang Dewasa (POD). Penyuluhan kepada masyarakat dibagi menjadi tiga bagian, yaitu pembagian panduan/leaflet, penyampaian materi, diskusi dengan contoh kasus, dan pembagian kotak sampah secara langsung. Penyampaian materi dikhususkan dalam berbagi pengetahuan kepada masyarakat sehingga mereka mengetahui penggolongan sampah baik sampah organik dan anorganik dan cara pengolahannya. Pada kegiatan ini juga ditunjukkan secara langsung pada warga beberapa contoh teknik pengolahan sampah organik dengan teknik composting dan pengolahan produk sampah plastik yang dapat dijadikan kerajinan dalam industri kreatif. Hasil wawancara kepada masyarakat menunjukkan bahwa, (1) sebelum dan setelah penyuluhan terjadi peningkatan pengetahuan masyarakat tentang teknik pengolahan sampah basah dan sampah kering (2) sebagian besar masyarakat memperoleh pengetahuan baru tentang pengelolaan sampah basah menjadi pupuk cair organik dan composting, sedangkan sampah plastik dapat dibuat berbagai kerajinan yang memiliki nilai jual. Dengan demikian dapat disimpulkan bahwa kegiatan pengabdian memberikan dampak positif bagi warga RT 17 RW 04 Kelurahan 14 Ulu Palembang.
\end{abstract}

Kata kunci: Sampah; teknik pengolahan; organik; anorganik; pengomposan

\begin{abstract}
Waste is a big problem for all of us along with the increasing population and industrial growth rates. The waste management system requires the role of government and society is needed in creating a clean, neat and healthy environment. One of the efforts made is by conducting counseling on waste and various processing techniques, so it is expected to increase knowledge of clean and healthy life to reduce the number of people affected by the disease, and create a community that participated actively and consciously on eviromental hygiene. The method used in implementing community service is the participatory method or Adult Education (POD). Implementing community service is divided into three parts, namely the distribution of guides/leaflets, delivery of material, discussions with case examples, and distribution of garbage boxes directly. Submission of material specifically in sharing knowledge to the community so they know the classification and process of waste both organic and inorganic waste. This activity is also shown directly to the community, some examples of techniques for processing organic waste by composting techniques and processing of plastic waste products that can be used as a craft in the creative industry. The results of interviews with the community showed that, (1) before and after counseling there was an increase in community knowledge about wet and dry waste processing techniques (2) most of the community acquired new knowledge about managing wet waste into organic liquid fertilizer and composting, while plastic waste could made various crafts that have a selling value. Thus it can be concluded that community service activities have a positive impact on residents of RT 17 RW 04 Kelurahan 14 Ulu Palembang.
\end{abstract}

Keywords: Waste; processing techniques; organic; inorganic; composting 
Format Sitasi: Kholillah, Astriani M., Angraini, E. (2020). Penyuluhan Teknik Pengolahan Sampah Rumah Tangga di Kelurahan 14 Ulu Palembang. Jurnal Solma. Vol. 09(2), 361-367. Doi: http://dx.doi.org/10.22236/solma.v9i2.3084

Diterima: 13 Februari 2019 | Revisi: 4 September $2020 \quad$ | Dipublikasikan 30 Oktober 2020

(C) 2020 Oleh authors. Lisensi Jurnal Solma, LPPM-Uhamka, Jakarta. Artikel ini bersifat open access yang didistribusikan di bawah syarat dan ketentuan Creative Commons Attribution (CC BY) license. (http://creativecommons.org/licenses/by/4.0/).

\section{PENDAHULUAN}

Masyarakat memiliki peran penting dalam mewujudkan lingkungan yang bersih, rapi, indah, dan sehat (Bara et al., 2018) Berdasarkan (Kepmenkes, 2017) No 32 tahun 2017 tentang standar baku mutu kesehatan lingkungan adalah situasi teknis yang dibakukan pada media lingkungan yang berhubungan atau berdampak langsung terhadap kesehatan masyarakat. Fakta di lapangan mengenai pencemaran yang ditimbulkan oleh sampah organik dan anorganik yang menyumbat selokan air menyebabkan perembesan yang dapat menimbulkan sumber penyakit bagi masyarakat sekitar. Rendahnya pengetahuan masyarakat terhadap lingkungan karena sangat sedikitnya sosialisasi di lingkungan masyarakat. Sosialisasi yang diberikan kepada masyarakat merupakan bentuk pendidikan dan pengetahuan mengenai lingkungan hidup masyarakat dalam upaya pencegahan penyakit. Menurut (Undang Undang, 2008) bahwa lingkungan hidup adalah kesatuan ruang dengan semua benda, keadaan, dan makhluk hidup, termasuk manusia dan perilakunya yang mempengaruhi alam itu sendiri serta kelangsungan perikehidupan dan kesejahteraan manusia serta makhluk hidup lain. Perlindungan dan pengelolaan lingkungan hidup merupakan upaya yang terpadu dalam melestarikan fungsi lingkungan dan mencegah terjadinya pencemaran atau kerusakan lingkungan hidup (Sauvé et al., 2016).

Lingkungan hidup yang harus diupayakan masyarakat yaitu menciptakan kondisi lingkungan yang higienis dengan menjaga pemukiman dari pencemaran air limbah rumah tangga dan pembuangan sampah. Kondisi lingkungan yang kurang baik dapat menimbulkan berbagai penyakit antara lain disentri, kolera dan penyakit diare lainnya, tipes, hepatitis, leptospirosis, malaria, demam berdarah, kudis, penyakit pernapasan kronis dan infeksi parasit usus (Novianti \& Pertiwi, 2018; Saleh \& Rachim, 2014; Windraswara \& Rizki, 2017). Menurut (Purnawijayanti, 2001) bahwa pencegahan dapat dilakukan dengan menghilangkan atau mengatur faktor-faktor lingkungan yang berkaitan dengan perpindahan penyakit dinamakan sanitasi.

Sanitasi yang baik dapat membuat keadaan lingkungan yang bersih dan aman dari berbagai penyakit serta memberikan pengaruh perilaku yang positif. Perilaku hidup sehat dan bersih dapat mencegah penyebaran penyakit (Kepmenkes, 2008). Lingkungan secara langsung maupun tidak langsung tercemar oleh tindakan manusia itu sendiri yang dapat mempengaruhi kesehatan manusia, walaupun kegiatan alam itu sendiri dapat mengakibatkan pencemaran lingkungan. Hal ini terlihat dari semakin menurunnya kualitas lingkungan dari hari ke hari. Berbagai penyakit timbul diakibatkan oleh sanitasi lingkungan yang tidak baik. 
Kegiatan penyuluhan mengenai sampah dan teknik pengolahannya sangat penting dalam memberikan arahan untuk mendukung pemerintah daerah dalam perencanaan, pelaksanaan, pemantauan, serta evaluasi program lingkungan bersih dari sampah (sanitasi lingkungan). Hasil wawancara terhadap perangkat RT 17 di Kelurahan 14 Ulu Palembang menyatakan bahwa penyuluhan yang berkaitan dengan pengelolaan lingkungan seperti teknik mengolah sampah belum ada. Ditambah permasalahan yang terjadi di daerah ini adalah kurangnya budaya membuang sampah pada tempatnya, karena lokasi ini belum menyediakan tempat sampah bagi warga sehingga warga tidak menjaga kebersihan dan kerapian lingkungan sekitar. Oleh karena itu, perlu dilakukan kegiatan penyuluhan bagi masyarakat di RT 17 RW 04 Kelurahan 14 Ulu Palembang. Pelaksanaan penyuluhan juga melibatkan orang tua, remaja, anak-anak yang perlu mendapat pendidikan mengenai sanitasi lingkungan dan hidup bersih bebas dari sampah. Pembinaan dan pendidikan mengenai kegiatan pengurangan sampah dengan mendaur ulang sampah, memanfaatkan kembali sampah, serta memilah sampah basah dan sampah kering. Pendekatan pengelolaan sampah dan teknik mengolahnya dilakukan bebasis masyarakat untuk membentuk masyarakat yang memiliki tanggung jawab, mandiri dalam mengembangkan pola hidup sehat dengan sanitasi lingkungan yang baik kepada anak, saudara, dan keluarga lainnya.

\section{MASALAH}

Hasil analisis permasalahan oleh tim pengabdian di lapangan diperoleh permasalahan diantaranya sanitasi lingkungan masih kurang diperhatikan, perilaku peduli lingkungan masih rendah, masih ditemukan sampah yang menyumbat selokan perumahan, dan tempat pembuangan sampah yang belum tersedia. Permasalahan ini muncul dikarenakan kurangnya kepedulian masyarakat terhadap lingkungan sekitar. Daerah ini belum ada program yang menggerakkan masyarakat untuk mengelolah sampah sehingga dianggap perlu mengarahkan masyarakat dalam mengelolah sampah. Penyuluhan sampah dan teknik pengolahannya diharapkan dapat meningkatkan pengetahuan masyarakat untuk mengurangi sampah basah dan sampah kering di rumah tangga, juga meningkatkan kepedulian dan bertanggung jawab terhadap lingkungan sekitar.

\section{METODE PELAKSANAAN}

Pemecahan masalah yang ada di keluruhan 14 Ulu Palembang adalah perlunya sikap peduli terhadap sampah, sehingga metode yang digunakan pada kegiatan yaitu partisipatif atau pendekatan kepada orang dewasa untuk melakukan penyuluhan mengenai sampah dan teknik pengolahannya (Sintiawati \& Fajarwati, 2019).

Selanjutnya dijelaskan mengenai teknik pengumpulan data, teknik analisis data, lokasi, waktu, dan durasi kegiatan.

Kegiatan dilaksanakan pada tanggal di kelurahan 14 Ulu Palembang, pada tanggal 30 Mei 2016. Susunan kegiatan penyulhan ini terdiri atas:

a. Absensi dan Pembukaan

b. Pemberian modul/leaflet

c. Penyampaian materi mengenai sampah dan teknik pengolahan dengan metode ceramah, dan dibantu menggunakan slide dan video 
d. Evaluasi (tanya jawab) dan pemberian cinderamata (tempat pembuangan sampah yang terpisah antara sampah organik dan anorganik)

e. Penutupan

\section{PEMBAHASAN}

Pelaksanaan pengabdian masyarakat ini, dibagi menjadi tiga bagian, yaitu pembagian panduan/leaflet, penyampaian materi, diskusi dengan contoh kasus, serta pembagian kotak sampah secara langsung.

\section{Pembagian panduan/Leaflet}

Modul atau Leaflet sederhana berisi materi penggolongan sampah dan teknik pengolahannya. Informasi dalam leaflet memuat materi pengenalan sampah dan pembagian sampah basah dan sampah kering. Beberapa prosedur yang dijelaskan dalam leaflet yaitu langkah kerja membuat kompos dan pupuk cair organik dari sampah rumah tangga. Informasi disampaikan dengan menayangkan video cara pembuatan kompos sesuai dengan langkah yang ada dalam leaflet. Teknik pengolahan basah skala rumah tangga dapat dilakukan masyarakat dan diterapkan dalam kehidupan sehari-hari untuk menyuburkan tanaman dan meningkatkan penghijauan di lingkungan. Selain itu sampah kering seperti botol plastik, kantong plastik, kaleng, dan bahan gelas disampaikan dengan media visual berupa foto dan gambar. Proses daur ulang untuk mengelolah sampah anorganik diubah menjadi produk tas, barang-barang seperti vas bunga dari botol plastik, cinderamata, atau hiasan-hiasan lainnya yang mempunyai nilai ekonomis (Kristianingrum, 2012).

\section{Penyampaian Materi}

Materi disampaikan oleh tim pengabdian masyarakat, meliputi pengenalan terhadap sampah dan masalah penanggulangan sampah. Pengenalan sampah kepada masyarakat ini bertujuan agar masyarakat dapat membedakan antara sampah organik dan anorganik. Selain itu, masyarakat diberikan penyuluhan mengenai solusi cara pengolahan sampah organik dan anorganik dengan menggunakan berbagai media informasi baik berupa power point maupun video. Waktu yang dialokasikan pada sesi ini adalah 20 menit (Gambar 1).

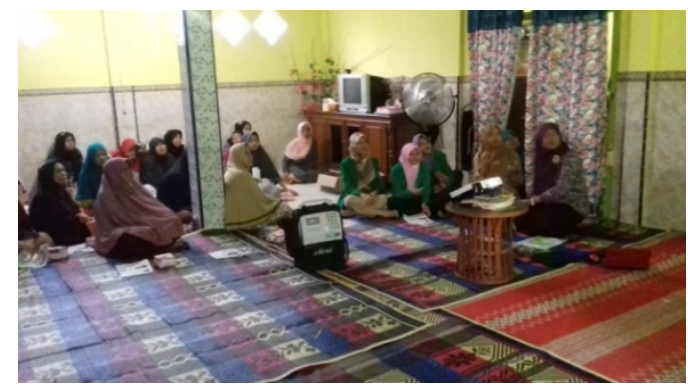

a

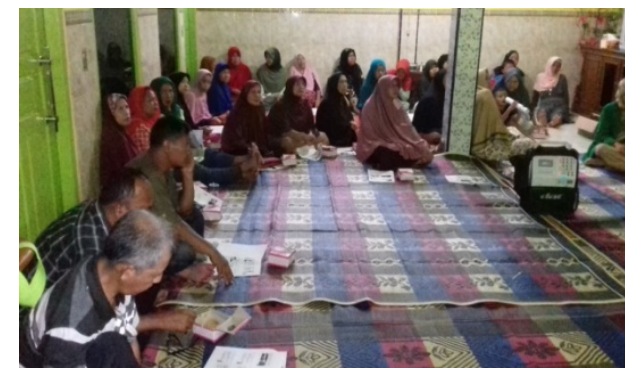

b

Gambar 1. Suasana kegiatan pengabdian kepada masyarakat (a) Penjelasan materi oleh tim saat kegiatan berlangsung, (b) berdiskusi

\section{Diskusi dengan Contoh Kasus}

Dialog bertujuan untuk memberikan kesempatan kepada peserta kegiatan untuk dapat melakukan klarifikasi tentang materi yang disampaikan dan berbagi pengalaman pribadi dalam hal mengolah sampah basah dan kering. Sesi ini merupakan tahap akhir, 
dimana setelah penjelasan teori, pembagian leaflet sederhana yang telah dibuat. Tahap ini dilakukan sebagai bentuk evaluasi pemahaman masyarakat setelah mendapatkan pengetahuan dalam bentuk diskusi atau tanya jawab dengan pertanyaan essay. Alokasi waktu adalah 45 menit. Pada kegiatan ini juga ditunjukkan secara langsung pada warga beberapa contoh teknik pengolahan sampah basah seperti Teknik pembuatan composting, pupuk cair organik, sedangkan pengolahan sampah kering seperti plastik yaitu memberikan arahan kepada ibu-ibu PKK untuk mewujudkan kerajinan industri kreatif. Hal tersebut sangat penting, sehingga dapat membantu masyarakat dalam mendaur ulang sampah yang memiliki nilai ekonomis.

Bentuk kontribusi masyarakat dalam penyuluhan adalah berpartisipasi dalam kegiatan dengan mendengarkan materi dan aktif dalam berdiskusi tentang permasalahan yang dihadapi dan bagaimana cara menyelesaikannya. Adapun hasil wawancara yang dilakukan sebelum penyuluhan dan setelah dilakukan penyuluhan secara lengkap disajikan dalam bentuk Tabel 1.

Tabel 1. Deskripsi wawancara sebelum penyuluhan dan setelah dilakukan penyuluhan

\begin{tabular}{clll}
\hline No & \multicolumn{1}{c}{ Parameter } & Sebelum Penyuluhan & Setelah Penyuluhan \\
\hline $\mathbf{1}$ & $\begin{array}{l}\text { Penggolongan } \\
\text { sampah }\end{array}$ & Sedikit yang mengenal & $\begin{array}{l}\text { Sebagian besar sudah } \\
\text { memahami }\end{array}$ \\
$\mathbf{2}$ & $\begin{array}{l}\text { Pengolahan sampah } \\
\text { basah }\end{array}$ & Sedikit mengetahui & Sebagian besar mengetahui \\
$\mathbf{3}$ & $\begin{array}{l}\text { Pengolahan sampah } \\
\text { kering }\end{array}$ & Sedikit mengetahui & Sebagian besar mengetahui \\
\hline
\end{tabular}

Sumber: Hasil Evaluasi Kegiatan

Pemberian kotak sampah dilakukan pada akhir kegiatan sebagai bentuk pengenalan kepada masyarakat untuk membedakan sampah basah dan kering. Sampah basah yang dihasilkan dari rumah tangga agar dapat dipilah untuk memudahkan masyarakat dalam membuat kompos dan pupuk cair. Sampah kering dipisahkan untuk di daur ulang menjadi kerajinan. Evaluasi kegiatan pada (Tabel 1) diperolah peningkatan pengetahuan masyarakat sebelum penyuluhan dan setelah penyuluhan. Pengetahuan masyarakat terhadap penggolongan sampah sebelum kegiatan masih sangat sedikit yang membedakan penggolangan sampah, setelah dilakukan kegiatan sebagian besar mengetahui penggolongan sampah dan teknik pengolahan sampah.

\section{KESIMPULAN}

Kegiatan penyuluhan sampah secara keseluruhan mencapai target yang diinginkan. Pemahaman masyarakat meningkat setelah diberikan penyuluhan tentang penggolongan sampah dan dan teknik pengolahannya. Untuk lebih meningkatkan kepedulian masyarakat terhadap sampah diperlukan kerja bakti secara rutin setiap minggu dalam rangka pembersihan jalan, selokan disekitar pemukiman penduduk, serta peran perangkat daerah seperti ketua RT, RW yang menggerakkan masyarakat dan melakukan sosialisasi antar RT sekitar untuk bekerja sama dalam melakukan pengelolahan sampah, baik sampah organik maupun anorganik. Diharapkan juga peran dinas kesehatan kota yang memfasilitasi sarana pembuangan sampah bagi masyarakat. 


\section{UCAPAN TERIMA KASIH}

Terima kasih kepada Lembaga Penelitian dan Pengabdian Kepada Masyarakat (LPPM) Universitas Muhammadiyah Palembang atas dukungan pendanaannya melalui hibah PKM No:188/H-6/LPPM/UMP/X/2016, juga kepada Dekan FKIP, ketua RT dan RW serta masyarakat RT 17 RW 04 Kelurahan 14 Ulu Palembang sehingga pengabdian ini terlaksana dengan baik.

\section{DAFTAR PUSTAKA}

Bara, D., Lasut, J. J., \& Goni, S. Y. (2018). Peran Disiplin Masyarakat dalam menjaga Budaya Hidup Bersih Terhadap Lingkungan (Suatu Studi di Desa Tuabatu Kecamatan Tampan Amma Kabupaten Talaud). Holistik, Journal Of Social and Culture, 11(21), $1-20$.

Kepmenkes, R. (2008). Nomor 852/MENKES/SK/IX/2008 tentang Strategi Nasional Sanitasi Total Berbasis Masyarakat.

Kepmenkes, R. (2017). Nomor 32 Tahun 2017 tentang Standar Baku Mutu Kesehatan Lingkungan dan Persyaratan Kesehatan Air untuk Keperluan Higiene Sanitasi, Kolam Renang, Solus Per Aqua, dan Pemandian Umum.

Kristianingrum, K. (2012). Pengolahan Sampah Kaca/Gelas Menjadi Aneka Produk Kerajinan Tangan. Laporan PPM. Universitas Negeri Yogyakarta.

Novianti, D., \& Pertiwi, W. E. (2018). Implementasi Sanitasi Lingkungan di Sekolah Dasar: Laporan Inspeksi 2018 dari Kecamatan Kramatwatu, Kabupaten Serang, Provinsi Banten. Jurnal Kesehatan Lingkungan, 11(3), 175-188.

Purnawijayanti, H. (2001). Sanitasi Higiene dan Keselamatan Kerja Dalam Pengolahan Makanan. Kanisius.

Saleh, M., \& Rachim, L. H. (2014). Hubungan Kondisi Sanitasi Lingkungan dengan Kejadian Diare pada Anak Balita di Wilayah Kerja Puskesmas Baranti Kabupaten Sidrap Tahun 2013. Jurnal Kesehatan, 7(1), 221-233.

Sauvé, S., Bernard, S., \& Sloan, P. (2016). Environmental sciences, sustainable development and circular economy: Alternative concepts for trans-disciplinary research. Environmental Development, 17, 48-56.

Sintiawati, N., \& Fajarwati, S. R. (2019). Partisipasi Orang Dewasa dalam Sebuah Pelatihan. Indonesian Journal of Adult and Community Education, 1(1), 26-30.

Undang Undang, U. U. R. (2008). Undang-Undang Republik Indonesia Nomor18 Tahun 2008 Tentang Pengelolaan Sampah.

Windraswara, R., \& Rizki, A. F. (2017). Analisis Daerah Rawan Air Dan Rawan Penyakit Berbasis Lingkungan Pada Daerah Padat Penduduk Dengan Water Stress Index Calculation. Journal of Health Education, 2(2), 164-171. 